\title{
Environmental Legislation of Russia and China: Common and Peculiar Features
}

\author{
Aleksey Pavlovich Anisimov ${ }^{1}$ and Anatoliy Yakovlevich Ryzhenkov ${ }^{2}$ \\ ${ }^{1}$ Professor Chair of Civil Law, Volgograd Institute of Business, Russian Federation \\ ${ }^{2}$ Professor Chair of Civil Law, Volgograd Institute of Business, Russian Federation
}

\begin{abstract}
The article presents a comparative legal analysis of the environmental legislations of Russia and China. As a result, common and peculiar legislative approaches of the two countries towards legal regulation of environmental protection are revealed. The main lines of comparison are associated with terminology issues, environmental protection procedures, presence of environmental requirements in certain fields of activities, securing of environmental rights of the citizens, contents of the certain norms of protection of natural resources. The most successful regulatory solutions of the environmental problems in the environmental legislations of China and Russia are suggested for the parliamentarians of the both countries to enhance the national environmental legislations. The obtained results could be used in further scientific research in the field of comparative environmental legal science as a new area of scientific investigations in various countries of the world. In order to achieve the set goals, the authors widely applied the system analysis method and the method of comparative legal research.
\end{abstract}

Keywords: Environment, natural resources, pollution, norm setting, supervision, ecological disaster zone, nature reserve, quality of life

\section{Introduction}

Modern legal science pays increasingly greater attention to such a method of scientific knowledge as a method of comparative jurisprudence. Its significance is based on the fact that it makes it possible to distinguish similar phenomena from dissimilar ones, to highlight common and specific features, to classify phenomena and to develop ideas regarding them. There is no science which would not apply comparison. It allows to differentiate the branches of the existing law (for instance, environmental law from administrative one, civil procedure from criminal one), certain legal institutions (for instance, sales and exchange, a contractor's agreement and an employment contract, invalidity and termination of agreements) to explain their historical development or to ground application of a law by analogy to similar but directly not settled cases (Stalev, 1978).

This method is quite widely applied in the science of Russian environmental law as well. In such research environmental legal comparison of the state of constitutional environmental rights of man in Russia and foreign countries holds the central place (Penkovsky, 2011 \& Trudova, 2008), more rarely a comparative analysis of environmental laws of different countries, for instance, in the post-Soviet states, is applied (Pankratov, 1996). However, for the time being comparative legal research of the environmental legislation of Russia and its closest neighbors is not carried enough.

In this regard a work by Liu Hongyan titled "Development of environmental law of China and Russia" (2008) is of particular importance for development of comparative environmental jurisprudence. It presents a summary of some results of development and mutual influence of the two national legal systems and interesting conclusions. As it was stated by the abovementioned author, comparative environmental law, as one of the basic branches of comparative jurisprudence, defined the general trend in the establishment of a complex legislative regime governing the area of protection of the environment and natural resources in some countries, similar to or approaching the level of development of a civilized society. Comparative environmental law encourages the development of environmental law in its state and can also raise the level of the national environmental legislation (Hongyan, 2008).

Therefore, the aim of this article is to continue the comparative legal research in the environmental legislation of Russia and China focused on detection of common and specific approaches to legal protection of the environment. This research could be of interest for parliamentarians of the two countries, for businessmen of the two countries having a negative effect on the environment, as well as for the public environmental organizations.

Russia and China have a long-term complex history of relations with both alliances and 
conflicts. Nowadays in the age of globalization new tasks which our countries may not solve separately are added to the agenda. Cooperation in the area of environmental protection, which knows no national borders, is one of such tasks. Russia and China have already taken a number of steps towards each other in this area. Agreement between the Government of the RF and the Government of the PRC about cooperation in the field of rational use and protection of the transboundary waters (January 29, 2008), for example, should be noted as one of such steps. On November 12, 2008 the Memorandum between the Ministry of Natural Resources and Environment of the RF and the Ministry of Environmental Protection of the PRC regarding development of a mechanism for notification and information exchange in transboundary issues of environmental nature was signed. It is especially important to note creation of joint specially protected natural areas. Thus due to the Agreement between the Government of the RF and the Government of the PRC of April 26, 1996 the international nature reserve was created at Lake Khanka. It includes Khankaysky State Nature Reserve (Primorsky Krai) and Lake Khanka Nature Reserve (Heilongjiang Province).

Continuation of such cooperation requires considerable research in Russian and Chinese environmental legislations, both in order to use the positive law-making and law-enforcement experience and to develop a joint environmental strategy.

\section{Main Areas of a Comparative Analysis of the Environmental Legislation of the Russian Federation and China in the Context of Predocrinal Interpretation of Environmental Law}

1) environmental requirements are included in the Constitutions of both the PRC and the RF. It is stated in the Constitution of the People's Republic of China 1982 (Art.9) that the state takes measures to protect and enhance the environment, fights the pollution and other public harm. The state guarantees rational use of natural resources, protects valuable species of animals and plants. None of organizations or individual persons are entitled to appropriate or destroy natural resources in any way.

The Constitution of the Russian Federation 1993, in its turn, includes a more detailed definition of environmental rights and obligations. According to Art.42 of the Constitution of the RF everyone shall have the right to a favourable environment, reliable information about its state and to restitution for damage inflicted on his health and property by ecological transgressions. The term "everyone" in Russian constitutional right is understood as any person (citizen of Russia, stateless person, foreign citizen) located in the territory of the Russian
Federation. Art.58 of the Constitution of the RF states legal obligations as well: to preserve nature and the environment, treat carefully the riches of nature.

2) Scientific legal comparison of the main environmental laws of Russia and China is of most interest. However, before making a number of suggestions regarding this issue, we would like to pay attention to a significant doctrinal point. In Russian environmental law for several decades there has been a dispute between the supporters of the "broad" and "narrow" views of the subject of the environmental law. The supporters of the "broad" approach consider that the environmental law as a branch of law includes nature resources (land, water, mining, forest, faunistic and air) law and nature conservation law (includes provisions on environmental management, responsibility for environmental breaches of law, peculiarities of environmental protection in certain areas of human activity or in certain specially protected areas, etc.).

Meanwhile, the supporters of the "broad" approach suggest adoption of the Environmental Code, which includes norms both of nature resources and environmental legislations. In addition, they believe that the environmental law governs issues of ownership of natural resources (Brinchuk, 2009).

Opposing to them the supporters of the "narrow" approach to interpretation of the environmental law believe that land, water, mining and other branches of nature resources law are of independent nature, despite the close connection with the issues of environmental protection. They are equally closely connected with civil, administrative, criminal and other branches of law, which, however, provides no reasons to mix them and to declare them one and the same branch of law.

Consequently, according to the opinion of this school of thought the draft Environmental Code should include not several thousands of articles governing issues of ownership of natural resources (as well as licensing, assignment for use, etc.), but only a few dozens of articles governing directly issues of environmental protection. Land, water, forest and other relations regarding use and protection of natural resources should be governed by nature resources laws.

Exactly this view is now supported by a Russian legislator who developed the Federal Law of January 10, 2002 "On Environmental Protection" according to the "narrow" model. Analysis of the Environmental Protection Law of the PRC of December 26, 1989 shows that the Chinese legislator also adheres to the concept of the "narrow" interpretation of the scope of environmental law. Like in Russia, where the Forest Code, the Water Code, the Law of the RF "On subsoil" and other nature resource laws are 
applied, the PRC adopted the Forest Code of the PRC, Mineral Resources Law of the PRC, etc.

3) Comparing the norms of the environmental laws of Russia and China we could point out a number of both common and different concepts, norms and procedures.

a) comparing the terminology of the two main environmental laws of Russia and China we could make a conclusion that in the PRC (Art.2 of the Environmental Protection Law of the People's Republic of China) the term "environment" refers to all natural elements and artificially modified natural elements affecting the human life, including atmosphere, water, seas, land, minerals, forests, meadows, wild life, traces of activity of nature and people, natural reserves, historic and natural sites, rural and urban areas.

In Russia we observe the same principle terminological approach. In Art.1 of the Federal Law of January 10, 2002 "On Environmental Protection" "the environment" "implies the complex of components of the natural habitat, natural, natural and man-made objects, as well as man-made objects", and, for example, "a natural and man-made object" implies a natural object modified as a result of economic and other activities and (or) object created by man, with features of a natural object and of a recreation and protection significance.

Consequently, our interpretations of the environment as a complex of natural and artificially modified environmental systems in general coincide. However, there are a number of differences in interpretation of protection objects. In China they are considered to include, for example, meadows or traces of human activity; in Russia such terms are not used, but, besides the land, soil is singled out as a protection object. Moreover, in Russia the objects of environmental protection are more widely represented today, which is caused by different dates of adoption of the laws being analyzed. That is why mentioning of the ozone layer and the circumterrestrial space as protection objects in Russian law should be considered more successful.

The issue regarding the best available environmental technologies should be noted in the terminological block. In Russia the best available technology is the technology based on the latest achievements of science and engineering, aimed at reduction of a negative impact on the environment and having a set period of application in practice with due consideration of economic and social factors. The PRC has no similar term, however, Art.25 of the Law of the PRC contains a provision stating that, in order to technologically transform new and already existing industrial enterprises, one should use structures and technological processes which allow to achieve a high level of utilization of resources and a low level of waste discharge. At the same time saving and rational technologies of comprehensive waste utilization and processing of polluting substances should be applied. Here we could see a certain similarity.

b) Russian and Chinese laws use different legal methods of formulation of environmental rights of citizens. Art. 6 of the Law of the PRC states that all organizations and individual persons shall protect the environment and be entitled to inform or bring accusations against organizations or individual persons polluting the environment or causing damage to it. Despite the content and persuasiveness of this statement we should note that the Law of the RF contains a more exhausted list of environmental rights of citizens, including a right to information about the environment, consolidation, appeal, environmental meetings, pickets and manifestations, etc. Environmental obligations are set in the same broad way. Thus the Russian legislator specifies in detail not only the rights and obligations of the citizens, but also the rights and obligations of public associations established by them.

c) analyzing the general provisions of the environmental laws of the RF and the PRC we should note that most regulatory approaches to environmental protection significantly coincide. Thus mandatory presence in the RF and the PRC of schedules and programs regarding environmental protection, measures for development of environmental education, science, development of environmental monitoring, informing of population about state of the environment etc. should be attributed to the number of common approaches. The similar approach is observed regarding the state regulation of standards of quality of the environment.

According to Art.9 of the Environmental Protection Law of the PRC the authorized department of the Environmental Protection Directorate under the State Council of the PRC establishes general national standards of quality of the environment. Administrations of provinces, autonomous regions and municipalities directly subordinated to the central government may establish local standards of quality of the environment in cases when general national standards of quality of the environment are not determined; they also may submit them for registration to the competent department of the Environmental Protection Directorate under the State Council of the People's Republic of China.

In the Russian Federation the norms of quality of the environment are established on the federal level (Art.5 Law of the RF on Environmental Protection), however, subjects of the Federation may set norms of quality of the environment stipulating corresponding requirements and norms not lower than the requirements and norms established on the federal level (Art.6). Meanwhile 
we should note that the local government bodies in Russia are not entitled to establish local standards of quality of the environment.

Thus within the framework of the comparison being carried out we note that the local (municipal) level of government in China has much more environmental authorities than the local level of government in Russia.

Much more common features in environmental laws of the PRC and the RF may be discovered regarding liabilities. Both countries have such sanctions as suspension (and even cessation) of activity, penalties, indemnification of damage. Meanwhile in the PRC, as well as in Russian law, in case of pollution of the environment through irresistible natural disasters which could not be prevented even by the modern way of taking reasonable measures, the corresponding party shall be exempted from the liability. In case the breach of the law causes serious pollution of the environment which seriously damages state or personal property or damages health and leads to death of people, in accordance with the law in the PRC the persons directly liable for the accident are criminally prosecuted.

In the Russian Federation the whole system of measures for environmental protection could be divided into measures of general nature (environmental supervision, responsibility, etc.) and measures of specific nature (requirements for certain types of activities; creation of territories with a special environmental and legal status; special measures for protection of separate types of natural resources).

In general we also observe such a model in the environmental legislation of the PRC as well. Besides the above-mentioned measures of general nature measures of specific nature are provided for in the PRC. According to Art.13 Law of the PRC organizations engaged in construction of facilities polluting the environment shall comply with the corresponding state provisions regarding protection of the environment. This group also includes measures for protection of the environment in agriculture (Art.20 Law of the PRC), protection of sea waters against pollution (Art.21), fulfillment of the environmental requirements within settlement planning (Art.22), introduction of special requirements for production, warehousing, transportation, sales and use of toxic chemical substances and materials containing radioactive contaminants, etc.

Similar above-mentioned requirements are stipulated in the Law of the RF as well. The only difference consists in that that these norms are more detailed in Russian law, and the very norms comprise a much greater number than in the law of the PRC.

Another variety of measures of specific nature presented in the environmental laws both in Russia and in the PRC includes creation of territories with a special environmental and legal status. Such territories may be of two types: specially protected natural areas and ecological disaster zones. They have a special status because they are not ordinary territories condition of natural complexes in which either much more better than common one (a nature reserve) or much worse (an ecological disaster zone). The latter variety of territories is not presented (though mentioned) in Russia and not mentioned in the Environmental Protection Law of the PRC.

The situation with regulation of a legal status of specially protected natural areas is considerably better in the both countries. In Russia such areas are called nature reserves, national parks, preserves, natural monuments, etc. The PRC also have nature reserves and other specially protected natural areas, and, in addition, administrations of different levels are liable for taking measures for protection of regions which are various types of natural environmental systems, regions with rare and endangered species of animals and plants, regions with preserved main sources of drinking water, with geological structures of a great scientific and cultural value, famous regions with karst caves and ancient deposits, traces of the ice age, volcanoes and thermal springs, elements of the human history, ancient and valuable species of trees.

It is no wonder that measures for protection of such valuable areas coincide as well, for example, regarding a ban on construction of industrial facilities there or mandatory reduction of discharged wastes.

A third block of Russian environmental legislation includes norms of protection of certain natural resources. Such norms may be presented both in the basic Law of the RF on Environmental Protection and in the nature resource laws (Forest Code of the RF, Water Code of the RF, etc.). The legislator of the PRC bases on similar views. For instance, Art.21 of the Forest Code of the PRC stipulates a range of measures for protection of forests against fire, Art.22 regulates organization of preventive measures against forest diseases. Measures with analogous contents are stipulated in the Forest Code of the RF as well.

\section{Possible Ways of Mutual Use of the Experience in Legal Regulation of Environmental Relations in Russia and China}

Environmental protection legislations of the PRC and Russia are formed in comply with the similar model, according to which environmental law governs issues of environmental protection and natural resource law governs issues of use of natural resources (including issues of ownership).The cross point of the scopes of the 
environmental and nature resource legislations is provision of rational use of the natural resources. Many methods of environmental protection in the RF and the PRC considerably coincide. Environmental legal regulation in Russia is more complete regarding a number of issues, but there is also a number of environmental measures stipulated in the legislation of China which require further analysis in order to enhance the environmental legislation in Russia, including:

a) experience of the PRC in increase of environmental authorities of local government bodies is of interest for Russian legislator;

b) we should also pay attention to norms of the Law of the PRC dedicated to mediation procedures within consideration of environmental disputes. Art.15 of the Law of the PRC is notable in this regard, according to it prevention and control of pollution of the environment and the damage suffered by different administrative regions shall be performed by local administrations by means of negotiations or, upon the decision of the supreme administration, by means of mediation. In Russia mediation procedures are at the initial stage of their application and this experience for us may be useful;

c) in the Russian Federation government bodies of any level are not liable for the quality of the environment in their territories (the RF in the whole, a subject of the RF, a municipality). The environmental legislation just obliges them to take some or other measures to ensure high quality of the environment. The corresponding authorized persons do not have any (legal, political) liabilities for efficiency of such measures. Here it should be noted that Art.16 of the Law of the PRC states that "local administrations of different levels shall be liable for the high quality of the environment under their jurisdiction and take measures for enhancement of the environmental situation". Such experience is also interesting for Russia;

d) according to Art.28 of the Law of the PRC revenues received from penalties paid for excessive discharges of contaminating wastes shall be used for prevention and control of pollution and shall not be used for other purposes. This is the norm introduction of which in Russian environmental legislation has been the subject of a fight for a long time. Nowadays in Russia all environmental revenues received to the budget are not accumulated in order to solve environmental protection problems, but are "dissolved" in the income and expenses of the budget.

Besides the normative regulation of environmental protection issues, the lawenforcement practice of China establishing in the area of environmental protection is rather valuable for Russia. One of the positive examples here may be measures for transition to a "green economy". Such measures were introduced in 2007 and first results have been achieved so far. This strategy shows a growth in electricity generation as a result of use of wind, solar batteries, thermal springs, a growth in production of environmentally-friendly cars (electrocars), creation of ecocities. Implementation of the latter project is provided by rapid development of "green construction" technologies for residential buildings. There are only some discussions in these areas in Russia, but the People's Republic of China takes decisive actions based on a substantial financing.

On an international scale the final concept of "green economy" appeared only at the UN Conference on Sustainable Development, RIO+20, which was held on June 20-22, 2012 in Rio de Janeiro (Brazil). It was decided that the "green" economy shall be considered in the context of sustainable development and liquidation of poverty as one of the essential instruments of sustainable development provision. Only the "green economy" may ensure different ways of policy formation. It should provide liquidation of poverty and a sustainable economic growth, social integration, enhancement of human wellbeing and creation of possibilities for employment and adequate work places for everybody, along with normal functioning of the ecosystems of the planet. The PRC already implements this concept.

The "environmental diplomacy" of China has reached great results. As it was mentioned in the scientific literature, it "is presented as activity of subjects of international relations regarding control of intergovernmental relationships in the area of environmental protection by means of negotiations and other peaceful means. The specificity of Chinese "environmental diplomacy" is characterized, on the one hand, as a way of protection of Chinese state domestic interests and opposition to pressure of more developed countries in environmental protection issues impeding environmental and economic development of China" (Kolpakova, 2009).

\section{Conclusions}

In conclusion we should note that the era of globalization and rapid development of science and technology leads to appearance of new threats for the environment and human health and life as well. Dealing with such threats in a single country is not possible, it requires both activation of international cooperation and harmonization of national legal systems. As one of such global threats we should mention influence of genetically modified products, nanotechnologies and nanomaterials (Anisimov, 2012) on a human organism, damage from implementation of space programs and nuclear electric stations, sharp deterioration of the environmental situation in some areas. Taking into account the complicated environmental situation in close proximity to the national border, in the future the Rus- 
sian Federation and the People's Republic of China may create an ecological disaster zone based on the method used in the nature reserve at Lake Khanka, where two halves of the territory are under jurisdiction of different countries, but the schedule of environmental actions is the same and coordinated. Such a polluted area could be organized on the banks of the Amur River.

We should also note the whole range of promising areas of cooperation between the two countries related to development of environmental tourism, environmental entrepreneurship (production of environmentally-friendly agricultural goods, rendering of environmental services, including environmental insurance), cooperation in the area of climate and protection of the ozone layer, maintenance of the biological diversity, fight against desertification, development of environmental culture, education, fight against environmental diseases, environmental migration, etc.

Such a list of measures will allow to defuse the controversy over the environmental issues in Russia and the PRC, to guarantee non-deterioration of life quality of the population; it will lower the level of international tension over the transboundary pollution of the water reservoirs and air of the both countries. Settlement of these and many other issues will require mutual understanding and cooperation both between the governmental bodies of the two countries and between representatives of the entrepreneurial structures and ordinary Russian and Chinese citizens.

\section{References}

Anisimov, A. (2012) Environmental protection against negative effect of nanotechnologies. Agrarian and land law,5,93-95.

Brinchuk, M. (2009) Environmental law: textbook. Moscow: Lawer. Hongyan, Liu (2008) Development of environmental law of China and Russia. Moscow: Gorodets.

Kolpakova, T. (2009) Political legal regulation of the social environmental process of the PRC under current conditions. Abstract of a thesis candidat of philosophical science. Chita: Chita state university, 9.

Pankratov, I. (1996) Comparative analysis of environmental protection laws of the CIS Countries. Bulletin of Moscow University. Series 11. Law, 1, 23-27.

Penkovsky, A. (2011) Constitutional right to favourable environmental in Russia and foreign countries. Comparative legal analysis. Law and right, 1, 37-39.

Stalev, Zh. (1978) Comparative method in socialist legal science. Logic and methodology of science. Comparative jurisprudence. Collection of articles. Moscow: Progress, 17.

Trudova, O., Yakovlev, E. (2008) On the question of classification, contents, legal enforcement of environmental rights of man and citizen (comparative analysis of legal systems of the RF and the European Union). International public and private law, 2, 22-25. 